\title{
Molecular Exploring of Plasmid-mediated Ampc beta Lactamase Gene in Clinical Isolates of Proteus mirabilis
}

Israa Abdul Ameer Al-Kraety', Sddiq Ghani Al-Muhanna' ${ }^{1}$, Shaima R. Banoon ${ }^{2}$

DOI. 10.21931/RB/2021.06.03.21

Abstract: Between September to December 2020, thirteen isolates of Proteus mirabilis were recovered among one hundred fifty; MacConkey agar was utilized to purify Gram-negative bacteria isolated from infections of the urinary tract. The primary identification of Proteus mirabilis isolates was relied on "colonial morphology, microscopic examination, and biochemical "tests; however, the confirmation of identification of antimicrobial susceptibility of isolates was conducted utilizing an automated VITEK-2 compact system. The result showed that Proteus mirabilis isolates were highly resistant to most antibiotics, making them multi-drug resistant (MDR). Phenotype methods were used to detect AmpC beta-lactamase. Initial and confirmatory methods showed that eight isolates were AmpC producers. Polymerase Chain Reaction (PCR) was employed to detect the bla $_{\text {ampc }}$ gene.

Key words: Proteus mirabilis, $\beta$-lactamase, blaampC, VITEK-2, PCR.

\section{Introduction}

Urinary tract infection (UTI) is a form of infection that affects the urinary tract. Microorganisms infecting or colonizing the urinary tract. The most common bacterial are pathogens in UTIs are P. aeruginosa, S. saprophyticus, E coli, and P. mirabilis ${ }^{1}$. Infections of the urinary tract can take place throughout the body. Urinary tract infections, such as cystitis, pyelonephritis, urethritis, prostatitis, and perinephritis ${ }^{2-5}$ affect people of all ages and are among the most widespread infectious diseases. Proteus mirabilis represents a Gram-negative bacterium famous for its ability to spread rapidly within a pattern resembling bulls' eyes. This organism is most commonly a urinary tract pathogen in clinical settings, especially in long-term catheterization patients. P. mirabilis uses urease and stone formation, fimbriae and other adhesives, iron and zinc conquest, proteases and toxins such as hemolysin and its function in pore formation, biofilm formation, and pathogenesis regulation to enter and colonize the host urinary tract $t^{6,7}$. The continuous usage of antibiotics produces the spread of antibiotic impedance and, in particular, to the progress of antibiotic resistance genes in gram-negative organisms, which are considered the most severe medical problems. For P. mirabilis the resistance to antimicrobials is growing ${ }^{8,9}$, including the resistance to expanded spectrum cephalosporin according to the production of expanded-spectrum $\beta$-lactamases (ESBLs) ${ }^{10}$. Although antibiotics are so valuable for treating many bacterial diseases, they are considered environmental contaminants in infected animals and humans for a long time ${ }^{38}$. This study aimed to detect Plasmid-mediated Ampc beta Lactamase Gene in Clinical Isolates of Proteus mirabilis at the molecular level.

\section{Methods}

\section{Sample's collection and identification}

During the study period from September to December 2020, the whole 150 midstream urine samples were obtained. The samples were taken from patients in Al-Najaf province hospitals who had urinary tract infections. Suspected $P$. mirabilis isolates were retrieved from clinical samples after purifi- cation on MacConkey agar and incubated aerobically overnight at $37^{\circ} \mathrm{C}$ and confirmed by biochemical tests. The definite identification was carried out using Gram-Negative - Identification (GN-ID) cards and VITEK 2 compact devices.

\section{Antibiotic Susceptibility Testing}

Using the automated VITEK-2 compact device and AST-N093 cards (bioMérieux, France), the Minimum Inhibitory Concentration (MIC) technique was calculated. This card composed the following antibiotics: Amikacin, Aztreonam, Cefepime, Ceftazidime, Ciprofloxacin, Colistin, Imipenem, Isepamicin, Gentamicin, Meropenem, Minocycline, Pefloxacin, Piperacillin, Piperacillin-Tazobactam, Rifampicin, Ticarcillin, Ticarcillin-Clavulanic acid, Tobramycin, Trimethoprim-Sulfamethoxazole.

\section{Exploring AmpC $\beta$-Lactamase}

\section{Initial Examination for AmpC $\boldsymbol{\beta}$-Lactamase Production}

Employing the standard disk diffusion process, all P. mirabilis isolates were checked for cefoxitin susceptibility using cefoxitin disk $30 \mu \mathrm{g} / \mathrm{ml}\left(\right.$ CLSI, 2019) ${ }^{11}$. Initially $14 \mathrm{~mm}$ inhibition zone diameter) were thought to be AmpC lactamase producers $^{12}$.

\section{Confirmatory Test for AmpC $\boldsymbol{\beta}$-Lactamase Product}

To detect plasmid-mediated AmpC B-lactamase, the AmpC disk test was used. The test involves permeabilizing a bacterial cell with Tris-EDTA and releasing $\beta$-lactamases into the surrounding medium. AmpC disks (i.e., filter paper disks consisting of Tris-EDTA) were made via immerse sterile filter paper disks with $20 \mu \mathrm{l}$ of a 1:1 mixture of normal saline and 100X Tris-EDTA, allowing the disks to dry, and storing them at 2 to $8{ }^{\circ} \mathrm{C}$. Using the typical disk diffusion process, a lawn of cefoxitin susceptible E. coli ATCC 25922 was spread on the surface of a Mueller-Hinton agar plate (CLSI, 2019). AmpC disks were rehydrated with $20 \mu \mathrm{l}$ of normal saline immediately before use, and several colonies of each research organism were added to the disk. On the inoculated surface of the Mue-

\footnotetext{
${ }^{1}$ Department of Medical Laboratory Techniques, Faculty of Medical and Health Techniques, University of Alkafeel, Najaf, Iraq
}

${ }^{2}$ Department of Biology, College of Science, University of Misan, Maysan, Iraq. 
Ller-Hinton agar, a $30 \mathrm{~g}$ cefoxitin disk occurred. After that, the inoculated AmpC disk was mounted on top of the antibiotic disk, with the inoculated disk face touching the agar base. After that, the plate was switched over and left to incubate at $37^{\circ} \mathrm{C}$ in ambient air overnight. After incubation, the plate was inspected, indicating the enzyme inactivation of cefoxitin or lack of distortion, indicating no apparent inactivation of cefoxitin (negative result) for indentation or flattening of the inhibition zone (negative result) ${ }^{13}$.

\section{Molecular Identification}

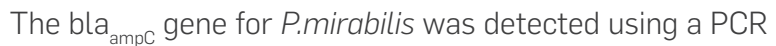
assay, as shown in Table (2). As shown in Table (1), this primer was developed by Alpha DNA Company in Canada. To estimate the size of the PCR products, $1 \%$ agarose gel electrophoresis was used to validate amplified products. The gel was stained with $5 \mu \mathrm{L}$ of $10 \mathrm{mg} / \mathrm{mL}$ ethidium bromide (Promega, USA) and run for 1.5 hours at 85 volts. On an ultraviolet light transilluminator (Cleaver, UK), one band was viewed at the required place; bands were produced employing a gel registration method "Cleaver, UK." The molecular weights of amplified items were calculated using a 100bp ladder "Bioneer, South Korea"14.

\section{Results and discussion}

Initial identification of bacterial isolates obtained from clinical samples was based on cultural morphology, microscopic characteristics, and biochemical examinations. The colonial morphology was employed to define the cultural identity of $P$. mirabilis from those isolates. P. mirabilis colonies are grown on blood agar and nutrient agar swarm in waves, while colonies grown on MacConkey agar ${ }^{15}$ do not swarm and form smooth colorless colonies, suggesting that P. mirabilis cannot ferment lactose sugar. P. mirabilis was Gram-negative bacilli organized separately, in couples, or short chains under microscopic examination. Table (3) displays the results of biochemical tests used to perform the initial identification of P. mirabilis insulates. The isolates shared oxidase-negative and catalase-positive characteristics in common. They were motile, methyl red, and gelatin liquefication positive for urease, catalase, citrate, urease, and gelatin. The isolates could sour glucose on Kliger iron agar, resulting in (Alkaline) red color on the slant and lower (acidic) yellow color with gas and H2S production ${ }^{16}$; oxidase, indole, and vogues-Proskauer were all negative $\mathrm{e}^{17,18}$.

The automated VITEK-2 compact device was utilized to complete the identification, including 47 biochemical tests and one negative control well on GN-ID cards. The findings show that only thirteen of 150 suspected isolates were emphasized as P.mirabilis, with ID message confidence levels varying from very good to excellent (Eventually from 93\% to 99\%).

\section{Antibiogram Testing and Minimum Inhibitory Concentration}

The automated VITEK-2 compact device was employed to test antibiograms. The analysis findings showed that all $P$. mirabilis isolates tested were resistant to at least three groups of antibiotics. As a result, all isolates were deemed multi-drug resistant (MDR). The findings showed that (100\%) of isolates were resistant to penicillins (piperacillin and ticarcillin), while (64.7\%) were resistant to both. Resistance to $\beta$-lactam- $\beta$-lactamase inhibitor was found in $100 \%$ of piperacillin/tazobactam and (47\%) of ticarcillin_clavulanic acid moreover resists to ceftazidime, cefepime, and cefoxitin" were identified in (100\%), (94.1\%) and (64.7\%), correspondingly, in the sample. Aztreonam resistance was 100 percent in all isolates. Low resistance was observed in the carbapenem community, which included imipenem and meropenem (the efficient $\beta$-lactam antibiotics), with the resistance of (5.9\%) for each. This finding was confirmed by (19), who found that P.mirabilis is (97.2\%) sensitive to this antimicrobial. Some Proteus mirabilis isolates have reduced resistance to imipenem for various reasons, including the lack of outer film porins, reduced expression of PBP1a, and decreased imipenem combining by PBP2 ${ }^{20}$. Because of the lack of $24 \mathrm{kDa}$ OMP, Proteus mirabilis has developed resistance to imipenem. Amikacin (70.5\%), isepamicin (64.7\%), tobramycin (53\%), and gentamicin (23.5\%) of the aminoglycoside population all had a significant intermediate effect on P.mirabilis insulates. These mechanisms of transmission effectively accelerate the spread of MDR bacteria causing nosocomial outbreaks worldwide ${ }^{21-23}$. Amikacin represents an aminoglycoside antibiotic that can be used to combat several bacterial infections. It works by interacting with the 30 s ribosomal subunit of bacteria, triggering mRNA misreading and preventing the bacterium from synthesizing important proteins for development. This finding agrees with (24), who found that (88.2\%) of insulates were resistant to pefloxacin and (64.7\%) of isolates were resistant to ciprofloxacin. (76.5\%) of insulates were impedance to trimethoprim-sulfamethoxazole, while (94.1\%) were impedance to minocycline, (25) observed that all insulates were impedance to both colistin and rifampicin. Susceptibility testing showed that none of the insulates were completely immune or susceptible to any of the antibiotics examined.

\begin{tabular}{|c|c|c|c|}
\hline Gene name & Primer Sequence (5'-3') & $\begin{array}{c}\text { Product } \\
\text { Size bp }\end{array}$ & Reference \\
\hline \hline AmpC & $\begin{array}{c}\text { F:ATCAAAACTGGCAGCCG } \\
\text { R: GAGCCCGTTTTATGCACCCA }\end{array}$ & $\mathbf{5 1 0}$ & 36 \\
\hline
\end{tabular}

Table 1. Primers employed in the current investigation.

\begin{tabular}{|c|c|c|c|c|c|c|}
\hline \multirow{3}{*}{$\begin{array}{l}\text { Gene } \\
\text { Name }\end{array}$} & \multicolumn{5}{|c|}{ Temperature $\left({ }^{\circ} \mathrm{C}\right) /$ Time } & \multirow{3}{*}{$\begin{array}{c}\text { Cycles } \\
\text { Number }\end{array}$} \\
\hline & \multirow{2}{*}{$\begin{array}{c}\text { Initial } \\
\text { Denaturation }\end{array}$} & \multicolumn{3}{|c|}{ Cycling conditions } & \multirow{2}{*}{$\begin{array}{c}\text { Final } \\
\text { Extension }\end{array}$} & \\
\hline & & Denaturation & Annealing & Extension & & \\
\hline$b^{\prime} a_{\mathrm{AmpC}}$ & $94 / 5$ mint & 94/30 sec. & $60 / 30 \mathrm{sec}$. & $72 / 30$ sec. & $72 / 10$ mint & 30 \\
\hline
\end{tabular}

Table 2. PCR program of ampC gene that applies in the thermocycler. 


\begin{tabular}{|l|l|c|}
\hline No. & Test & Result \\
\hline $\mathbf{1 .}$ & Oxidase & - \\
\hline $\mathbf{2 .}$ & Catalase & + \\
\hline $\mathbf{3 .}$ & Motility & + \\
\hline $\mathbf{4 .}$ & Indole & - \\
\hline $\mathbf{5 .}$ & Citrate Utilization & + \\
\hline $\mathbf{6 .}$ & Methyl Red & + \\
\hline $\mathbf{7 .}$ & Voges-Proskauer & - \\
\hline $\mathbf{8 .}$ & Klingler iron agar & + \\
\hline $\mathbf{9 .}$ & Urease & + \\
\hline $\mathbf{1 0 .}$ & gelatin liquefaction & + \\
\hline
\end{tabular}

Table 3. Conventional biochemical tests results of P.mirabilis suspected isolates.

\section{Exploring Phenotypic of Plasmid-Mediated AmpC $\boldsymbol{\beta}$-Lactamase (PMABL)}

Producing insulates phenotypic detection cefoxitin impedance was an initial screening marker for AmpC $\beta$-lactamase producers. The basic Kirby-Bauer disk diffusion approach was employed to test P.mirabilis insulates for cefoxitin susceptibility. Cefoxitin zone diameter less than $14 \mathrm{~mm}$ yielded Such impedance insulates were classified as AmpC $\beta$-lactamase producers, due to the Clinical and Laboratory Standards Institute's (2019) recommendation. According to the phenotypic data collected in this study, 10 (76.9\%) insulates were resistant to cefoxitin, while 2 (15.3\%) were intermediate, and 1 (7.6\%) was susceptible. The development of AmpC $\beta$-lactamase was screened in all isolates using the $\mathrm{AmpC}$ disk test, that $\mathrm{AmpC}$ producer was found in five (38.4\%) of the thirteen isolates with $5(62.5 \%)$ isolates resistant to cefoxitin, $2(25 \%)$ intermediate resistant isolates, and 1 (12.5\%) isolate susceptible to cefoxitin (Figure 1). The detection of plasmid-mediated AmpC-lactamases was calculated employing the AmpC disk test. The AmpC disk examination had $100 \%$ responsively and $98 \%$ mainly for detecting plasmid-mediated AmpC $\beta$-lactamases.

On the other hand, the phenotypic data revealed that the whole AmpC positive insulates had previously been identified as cefoxitin resistant ${ }^{26}$ However, this test was in cefoxitin susceptible, and intermediate resistant insulates not able to demonstrate the possibility of AmpC development. This may be because the $\mathrm{AmpC}$ disk test relies on the permeabilization of the cell membrane and the release of $\beta$-lactamases into the system. This examination may not identify low-level expression enzymes. According to (27) (22\%) of AmpC producers, insulates were susceptible to cefoxitin. The development of amps in these insulates may be according to a mechanism close to that of ESBL production organisms susceptible to ceftazidime when tested using the disc diffusion approach. Cefoxitin impedance in non-producers of $\mathrm{AmpC}$ may be following several mechanisms, including a lack of porin permeation (27). Occasionally, rather than AmpC enzyme activity, cefoxitin impedance results from producing several carbapenemases and a few forms of class $A \beta$-lactamases ${ }^{28}$.

\section{Molecular Exposure of Plasmid-Mediated AmpC $\beta$-Lactamase} (PMABL) Producing Insulates

The existence of the bla $a_{\text {ampc }}$ gene was investigated in thirteen isolates of P.mirabilis, with the results indicating that only
$5(38.4 \%)$ isolates yielded bla $a_{\text {ampc }}$ gene amplification products using specific primers (Table1). The identification of these isolates by PCR is depicted in (Figure 2). Several cellular functions ${ }^{29-32}$. Some Enterobacteriaceae family members such as "Enterobacter, Shigella, Providencia, Citrobacterfreundii, Morganellamorganii, Serratiamarcescens, and Escherichia coli"33-35 have AmpC $\beta$-lactamase genes on their chromosomes. As a consequence of this shift, plasmid-mediated ampC-lactamases have arisen. Plasmid-mediated AmpC-lactamases are a novel task since they impart carbapenem tolerance in strains missing outer membrane porins, have cephamycin impedance and are unaffected by commercially available -lactamase inhibitors. This mechanism of resistance has been discovered all over the world and has the potential to cause nosocomial outbreaks. It seems to be increasing, so more research is required to evaluate the best detection and treatment options ${ }^{37}$.

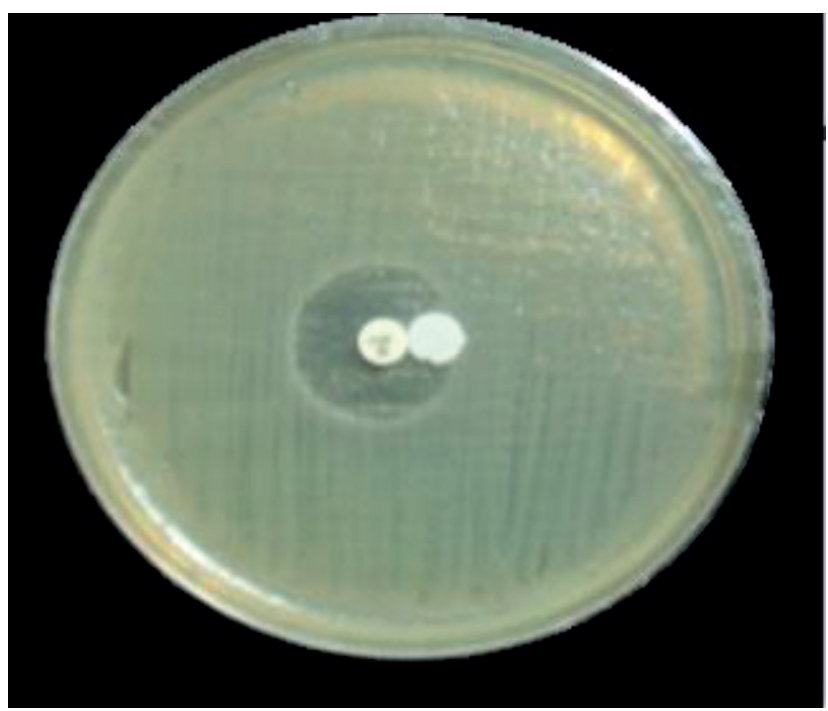

Figure 1. A positive result of a phenotypic confirmatory test for AmpC.

\section{Conclusions}

According to our knowledge, the present study revealed that chromosome $a m p C$ gene was detected on a plasmid of local Proteus mirabilis isolates. Show the result that Proteus mirabilis isolates were highly resistant to most antibiotics, making them multi-drug resistant (MDR). Meropenem and imipenem were highly active against P.mirabilis isolates. The simultaneous presence of ESBLs and AmpC $\beta$-lactamase was seen in several P.mirabilis isolates. The results indicating that only 5 (38.4\%) isolates yielded blaAmpC gene amplification products.

\section{Bibliographic references}

1. Foxman B. Urinary tract infection syndromes: occurrence, recurrence, bacteriology, risk factors, and disease burden. Infectious disease clinics of North America. 2013 Dec 8;28(1):1-3.

2. O'Hara CM, Brenner FW, Miller JM. Classification, identification, and clinical significance of Proteus, Providencia, and Morganella. Clinical microbiology reviews. 20001 October;13(4):534-46.

3. Nicolle LE. Catheter-related urinary tract infection. Drugs \& aging. 2005 Aug;22(8):627-39.

4. Jacobsen SÁ, Stickler DJ, Mobley HL, Shirtliff ME. Complicated catheter-associated urinary tract infections due to Escherichia coli and Proteus mirabilis. Clinical microbiology reviews. 20081 January;21(1):26-59. 


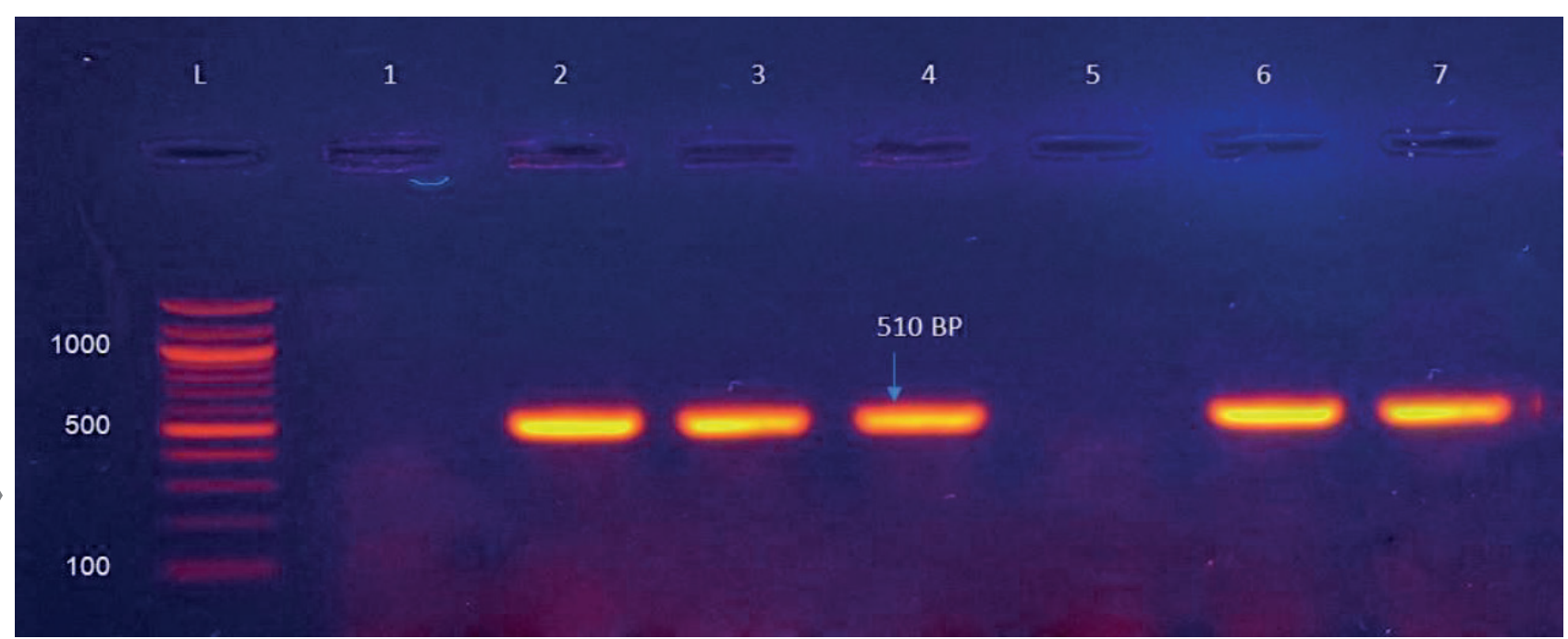

Figure 2. PCR production of P.mirabilis isolates dilated with bla ${ }_{\text {ampc }}$ primary genes, with a product size of 510 bp. (L): $100-b p$ ladder; Lanes $\left(2,3,4,6\right.$, and 7): positive bla ${ }_{\text {ampc }}$ gene results; Lanes $\left(1,5,8\right.$, and 9): negative bla ${ }_{\text {ampc }}$ gene results.

5. O'Brien VP, Hannan TJ, Schaeffer AJ, Hultgren SJ. Are you experienced? Understanding bladder innate immunity in the context of recurrent urinary tract infection. Current opinion in infectious diseases. 2015 Feb;28(1):97.

6. Massad G, Bahrani FK, Mobley HL. Proteus mirabilis fimbriae: identification, isolation, and characterization of a new ambient-temperature fimbria. Infection and immunity. 19941 May;62(5):1989-94

7. Zunino P, Geymonat L, Allen AG, Legnani-Fajardo C, Maskell DJ. Virulence of a Proteus mirabilis ATF isogenic mutant is not impaired in a mouse model of ascending urinary tract infection. FEMS Immunology \& Medical Microbiology. 2000 Oct 1;29(2):137-43.

8. Paterson DL, Yu VL. Editorial response: extended-spectrum 冈-lactamases: a call for improved detection and control. Clinical Infectious Diseases. 1999 Dec 1;29(6):1419-22.

9. Bradford PA. Extended-spectrum $囚$-lactamases in the 21st century: characterization, epidemiology, and detection of this important resistance threat. Clinical microbiology reviews. 20011 October;14(4):933-51.

10. Sohn KM, Kang Cl, Joo EJ, Ha YE, Chung DR, Peck KR, Lee NY, Song $\mathrm{JH}$. Epidemiology of ciprofloxacin resistance and its relationship to extended-spectrum $囚$-lactamase production in Proteus mirabilis bacteremia. The Korean journal of internal medicine. 2011 Mar;26(1):89.

11. Nasim K, Elsayed S, Pitout JD, Conly J, Church DL, Gregson DB. New method for laboratory detection of AmpC $\otimes$-lactamases in Escherichia coli and Klebsiella pneumoniae. Journal of clinical microbiology. 2004 Oct 1;42(10):4799-802.

12. Coudron PE, Hanson ND, Climo MW. Occurrence of extended-spectrum and AmpC beta-lactamases in bloodstream isolates of Klebsiella pneumoniae: isolates harbor plasmid-mediated FOX-5 and ACT-1 AmpC beta-lactamases. Journal of Clinical Microbiology. 2003 Feb 1;41(2):772-7.

13. Black JA, Moland ES, Thomson KS. AmpC disk test for detection of plasmid-mediated AmpC $\otimes$-lactamases in Enterobacteriaceae lacking chromosomal AmpC $囚$-lactamases. Journal of clinical microbiology. 20051 July;43(7):3110-3.

14. Levy H, Diallo S, Tennant SM, Livio S, Sow SO, Tapia M, Fields PI, Mikoleit M, Tamboura B, Kotloff KL, Lagos R. PCR method to identify Salmonella enterica serovars Typhi, Paratyphi A, and Paratyphi B among Salmonella isolates from the blood of patients with clinical enteric fever. Journal of clinical microbiology. 2008 1 May;46(5):1861-6.

15. Mahillon J, Chandler M. Insertion sequences. Microbiology and molecular biology reviews. 1998 Sep 1;62(3):725-74.

16. Matsen JM, Blazevic DJ, Ryan JA, Ewing WH. Characterization of indole-positive Proteus mirabilis. Applied microbiology. 19721 March;23(3):592-4.
17. Kishore J. Isolation, identification \& characterization of Proteus penneri-a missed rare pathogen. The Indian journal of medical research. 2012 Mar:135(3):341.

18. Kamga HL, Nsagha DS, Assob JC, Njunda AL, Tchape GN. Epidemiological studies on proteeae isolates from clinical specimens in the Laquintinie Hospital in Douala, Cameroon. African Journal of Clinical and Experimental Microbiology. 2012;13(2):118-26.

19. Al-Jumaily E, Zgaer SH. Multi-drug resistant Proteus mirabilis isolated from urinary tract infection from different hospitals in Baghdad City. Int. J. Curr. Microbiol. App. Sci. 2016;5(9):390-9.

20. Girlich D, Dortet L, Poirel L, Nordmann P. Integration of the bla NDM-1 carbapenemase gene into Proteus genomic island 1 (PGI1-Pm PEL) in a Proteus mirabilis clinical isolate. Journal of Antimicrobial Chemotherapy. 20151 January;70(1):98-102.

21. Koehn FE, Carter GT. The evolving role of natural products in drug discovery. Nature reviews Drug discovery. 2005 Mar;4(3):206-20.

22. Molinari G. Natural products in drug discovery: present status and perspectives. Pharmaceutical Biotechnology. 2009:13-27.

23. Hayashi MA, Bizerra FC, Da Silva Junior PI. Antimicrobial compounds from natural sources. Frontiers in microbiology. 201315 July;4:195.

24. Al-Muhanna AS, Al-Muhanna S, Alzuhairi MA. Molecular investigation of extended-spectrum beta-lactamase genes and potential drug resistance in clinical isolates of Morganella morganii. Annals of Saudi medicine. 2016 May;36(3):223-8.

25. Al-Muhanna SG, Banoon SR, Al-Kraety IA. Molecular detection of integron class 1 gene in proteus mirabilis isolated from diabetic foot infections. Plant Archives. 2020 Apr; 20(1): 3101-3107.

26. Black JA, Moland ES, Thomson KS. AmpC disk test for detection of plasmid-mediated AmpC $囚$-lactamases in Enterobacteriaceae lacking chromosomal AmpC $囚$-lactamases. Journal of clinical microbiology. 20051 July:43(7):3110-3.

27. Mohamudha PR, Harish BN, Parija SC. AmpC beta lactamases among Gram negative clinical isolates from a tertiary hospital, South India. Brazilian Journal of Microbiology. 2010 Oct; 41(3):596-602.

28. Jacoby GA. AmpC $\otimes$-lactamases. Clinical microbiology reviews. 20091 January;22(1):161-82.

29. Schmitzova J, Klaudiny J, Albert Š, Schröder W, Schreckengost W, Hanes J, Judova J, Šimúth J. A family of major royal jelly proteins of the honeybee Apis mellifera L. Cellular and Molecular Life Sciences CMLS. 1998 Sep;54(9):1020-30.

30.Albert S, Bhattacharya D, Klaudiny J, Schmitzová J, Simúth J. The family of major royal jelly proteins and its evolution. Journal of Molecular Evolution. 19991 August;49(2):290-7.

31. Kupke J, Spaethe J, Mueller MJ, Rössler W, Albert Š. Molecular and biochemical characterization of the major royal jelly protein in bumblebees suggest a non-nutritive function. Insect biochemistry and molecular biology. 2012 Sep 1;42(9):647-54 
32. Buttstedt A, Moritz RF, Erler S. Origin and function of the major royal jelly proteins of the honeybee (Apis mellifera) as members of the yellow gene family. Biological Reviews. 2014 May:89(2):255-69.

33. Medeiros AA. Evolution and dissemination of $囚$-lactamases accelerated by generations of $\otimes$-lactam antibiotics. Clinical Infectious Diseases. 19971 January;24(Supplement_1):S19-45.

34. Subha A, Devi VR, Ananthan S. AmpC beta-lactamase producing multi-drug resistant strains of Klebsiella spp. \& Escherichia coli isolated from children under five in Chennai. Indian Journal of Medical Research. 20031 January:117:13-8.

35. Mohamudha PR, Harish BN, Parija SC. AmpC beta lactamases among Gram negative clinical isolates from a tertiary hospital, South India. Brazilian Journal of Microbiology. 2010 Oct:41(3):596-602

36. Messai Y, Benhassine T, Naim M, Paul G, Bakour R. Prevalence of $囚$-lactams resistance among Escherichia coli clinical isolates from a hospital in Algiers. Rev Esp Quimioter. 2006 Jun 1;19(2):144-51.

37. Tan TY, Ng LS, He J, Koh TH, Hsu LY. Evaluation of screening methods to detect plasmid-mediated AmpC in Escherichia coli, Klebsiella pneumoniae, and Proteus mirabilis. Antimicrobial agents and chemotherapy. 20091 January;53(1):146-9.

38. Banoon S, Ali Z, Salih T. Antibiotic resistance profile of local thermophilic Bacillus licheniformis isolated from Maysan province soil. Comunicata Scientiae. 202013 July;11:e3921-.

Received: 10 April 2021

Accepted: 15 July 2021 